\title{
Professor Andrew Fielding Huxley, OM, FRS, 1917-2012
}

\author{
C. C. Ashley
}

(C) Springer Science+Business Media B.V. 2012

Andrew Huxley was born in London on 22 November 1917 a son of Leonard Huxley the writer and editor, who himself was a son of the distinguished nineteenth-century biologist and educator Thomas H. Huxley.

Andrew Huxley's interest in biology and physics were fostered at an early age at home with a gift to him and his brother both of a microscope and a lathe. An interest in physics at University College School and then at Westminster School, where he was King's Scholar, led to Cambridge where he read chemistry, physics and maths in Part I, with physiology as the required extra science paper. This latter subject brought him into direct contact in Cambridge with the likes of E. D. Adrian, Roughton, Rushton, Millikan and A. L. Hodgkin. It was with Alan Hodgkin that Andrew's abilities, both as a practical scientist able to make his own apparatus together with his outstanding ability to construct mathematical models based on critically determined experimental data, came to the fore and made him one of the leading scientists of his age. His work on the mechanism of nerve conduction led to the award the Nobel Prize in Physiology and Medicine in 1963 together with Sir Alan Hodgkin and the Australian neurophysiologist, Sir Jack Eccles. Andrew Huxley, at that time, had already turned to the subject of the nature of muscle contraction and together with his then collaborator Rolf Niedergerke, they published in the journal Nature in 1954, back to back with and independently from work by Hugh Huxley (no relation) and Jean Hanson, the idea of the Sliding-Filament Model of striated muscle contraction-a now well established mechanism which provided a framework for future work on muscle until now. 